\title{
RISPERIDONE INDUCED PEDAL OEDEMA IN A PATIENT OF SCHIZOPHRENIA: A CASE REPORT
}

\author{
Dr. Soumya Naskar', Dr. Pulakesh Sarmah², Dr. Kunal Deb ${ }^{3}$, Dr. L Longna ${ }^{4}$ \\ 1 PGT Second year, 2 PGT third year, ${ }^{3}$ Assistant Professor, ${ }^{4}$ PGT third year, LGBRIMH, Tezpur, Assam, India \\ (Received on Date: 17 March 2021 \\ Date of Acceptance: 18 March 2021 \\ Date of Publish: 19 March 2021)
}

email id-soumonaskar@gmail.com

\begin{abstract}
Risperidone is a second generation antipsychotic which is widely used in Schizophrenia and various other psychotic conditions. The main pharmacological action of Risperidone is by blocking Dopamine D2 receptors and Serotonin 5-HT2A receptors, thereby improving psychotic symptoms. Apart from common side effects like extrapyramidal symptoms, sedation etc. associated with risperidone, there are also rare side effects like pedal oedema as reported in few case studies. The mechanisms for Risperidone induced pedal edema could be multiple etiologies such as Risperidone has high affinity antagonism action on peripheral adrenergic al and a2 adrenergic receptors and Histaminergic $\mathrm{H} 1$ receptors, supersensitivity and vasodilatation theory, Allergic reaction etc. This case report illustrates pedal edema as one of the adverse effects of risperidone which was dose dependent side effect.
\end{abstract}

Keywords: Oedema, Drug, Risperidone 


\section{INTRODUCTION}

Risperidone, first synthesized in 1984 and being the first second generation antipsychotic to be approved following clozapine is a Benzisoxazole derivative. It is widely used in conditions like Schizophrenia, Bipolar disorder, irritability associated with Autism, etc. Its therapeutic actions are mediated by its potent antagonism at Dopamine D2 receptors and Serotonin 5-HT2A receptors. It also has high affinity for adrenergic al and a2 adrenergic receptors and Histaminergic $\mathrm{Hl}$ receptors.The common side effect associated with risperidone are extrapyramidal symptoms, orthostatic hypotension, anticholinergic side effects, sedation, etc.[1]. However a few case reports also mention the incidence of oedema in Risperidone. Pedal oedema has also been described with other antipsychotics besides Risperidone. Here we present a case who developed pedal oedema on increasing Risperidone and which resolves spontaneously on decreasing the dose.

\section{CASE DESCRIPTION}

A 23 years old male patient was brought with the chief complains of irrelevant talks, suspiciousness and aggression for about a period of 1 year. After proper assessment, he was diagnosed as a case of Paranoid Schizophrenia. The patient was admitted and started on injectable antipsychotics and sedatives for being uncooperative and being a potential risk of harming self and others. After 2 days tablet Olanzapine $10 \mathrm{mg}$ was started and was gradually increased to $20 \mathrm{mg}$ which was continued for more than 3 weeks. Since improvement was not noticed in the patient, he was started on tablet Risperidone $6 \mathrm{mg}$ after stopping Olanzapine. Risperidone was increased to $8 \mathrm{mg}$ after 1 week. After two days, the patient complained of painless swelling of both ankle joints. On examination, bilateral pitting oedema was noted. Investigations were done while Risperidone was continued at the same dose. Finding no other cause, Risperidone was decreased to $6 \mathrm{mg}$ per day. The bilateral pitting leg oedema subsided within a week.

When the patient was admitted routine blood investigations were done. On the day of admission, Hemoglobin was 10 $\mathrm{gm} / \mathrm{dl}$ and AST and ALT were $135 \mathrm{IU} / \mathrm{L}$ and $120 \mathrm{IU} / \mathrm{L}$ respectively. All other reports including renal function tests, thyroid function tests, routine urine investigations, ultrasonography of whole abdomen were within normal limits. After the development of oedema blood test were repeated. Improvement in hemoglobin profile and AST, ALT were noticed compared to previous reports which indicated that anaemia or compromised liver functions were not the causes of oedema. Ultrasonography whole abdomen was normal. Also no imbalance in serum urea or creatinine was noted suggesting no abnormalities of kidney function. After the pedal oedema subsided, blood tests were again repeated. Reports were consistent to the previous reports. The total score in Naranjo Adverse Drug Reaction Probability Scale was estimated to be 7 indicating a possible drug induced condition[2].

\section{DISCUSSION}

2021 March Edition | www.jbino.com | Innovative Association 
Oedema is a rare complication associated with risperidone. There have been some case reports showing the occurrence of oedema in a dosedependent manner with risperidone therapy.

Risperidone-related leg oedema occurs as an infrequent adverse effect in between $1 / 100$ to $1 / 1000$ cases. In our clinical practice in patients treated with Risperidone, oedema has not been noted. However, this finding might also be the result of insufficient awareness of this relatively rare adverse effect of risperidone. Sanders and Lehrer[3], reported a case of Risperidone induced generalised oedema in which oedema appeared when Risperidone was added to a regimen including Valproic acid and a Benzodiazepine.

Most cases of risperidone-induced oedema, the immunological and hematological blood tests reveal no abnormal findings and the actual mechanism of pathogenesis remains unclear.

\section{Possible mechanisms are:}

1) Supersensitivity and vasodilatation theory : Although Risperidone primarily acts as an antagonist at the serotonin2A/dopamine-2

(5HT2A/D2)-receptor system, it is also an antagonist at the alpha1- and alpha2-receptors of the noradrenergic system [4]. The (5HT2A/D2)receptor system occurs only in the central nervous system but the alpha-receptors of the noradrenergic system are present both in the central nervous system and in the 'peripheral system'. It may be that Risperidone's antagonistic action on the alpha-receptors of the peripheral vascular system causes vasodilation and raises the hydrostatic pressure in the blood capillaries. This hydrostatic pressure pushes the fluid from the intravascular compartment to the interstitial space, which results in oedema [5]. This state that there is super-sensitivity of a-receptors to antipsychotic which occurred especially during the "drug-free period". But there is no such drug free period in our case ruling out this possible mechanism.

2) Allergic reaction: Immune reaction may be implicated in the mechanism of drug-induced edema. Immune components that were reported in case reports include elevated immunoglobulin $\mathrm{E}$ and low C4 and Cl esterase inhibitor in relation to Risperidone [6,7]. Stimulation of IgE causes mast cell degranulation and swelling or oedema. The Type I and Type IV hypersensitivity reactions were considered to be responsible for the allergic reactions [8] (i.e. facial and pedal oedema, disseminated maculopapular drug eruption, urticaria) [9].

3) Another possible mechanism is renal dopamine receptor (D4)-mediated altered regulation of fluid and electrolyte balance by the kidney due to dopaminergic blockade by risperidone $[6,10]$. This might be a possible reason of risperidone-induced oedema. Our investigation shows normal level of serum urea and creatinine ruling out this possible mechanism.

4) Dose-response (dose-dependent) relationship: It states that, when risperidone dose is increased and rapidly, it can lead to development of oedema. On reduction of the dose, edema disappears. This dose-dependent theory is supported by Tamam et al. where within 1 week of reduction of risperidone dose, edema resolved [11]. Kores Plesnicar et al. reported that their patient that developed edema had her risperidone titrated from 2 to $6 \mathrm{mg}$ within 2 weeks 
$[12,13]$. Rapid dose increase of risperidonemay also be a factor in inducing peripheral edema. This might be the possible mechanism for our case.

Although there are previous published reports in the literature regarding oedema associated with risperidone use, our case was distinct in that the oedema rapidly developed in a week period, while in other reports the period of development was slightly longer, ranging from 2 weeks to 3 months, except for a case reported by Ravasia, where oedema developed in just 3 days with a low dose of risperidone [14].

The best treatment would be to discontinue risperidone and substitute it with another novel antipsychotic if necessary. However, if the drug is proven to be effective and appears to be the best choice of treatment in patients such as ours, it would seem appropriate to lower the drug dosage to a dose where the oedema resolves and follow up the patient more frequently [11].

\section{CONCLUSION}

This case report demonstrates the occurence of pedal oedema as one of the rare side effects of Risperidone. It further implies that modification of the dose can be one of the effective measures in its management.

\section{REFERENCES}

1. Kaplan HI, Sadock BJ. Comprehensive textbook of psychiatry, Vols. 1-2. Williams \& Wilkins Co; 1989table 34.28-2,side effects associated with receptor antagonism, second generation antipsychotic.
2. Naranjo CA, Busto U, Sellers EM, Sandor $P$, Ruiz I, Roberts EA, Janecek E, Domeca C, Greenblatt DJ. A method for estimating the probability of adverse drug reactions. Clinical Pharmacology \& Therapeutics. 1981 Aug;30(2):239-45.

3. Sanders RD. Valproate-related edema. Clinical neuropharmacology. 2001 Mar $1 ; 24(2): 123-4$.

4. Stahl SM, Stahl SM. Stahl's essential psychopharmacology: neuroscientific basis and practical applications (page no - 171). Cambridge university press; 2013 Apr 11.

5. Feroz-Nainar C, Selvaraj $P$, Roy $M$. Risperidone induced oedema in a child with learning disability and autism. Autism. 2006 May; 10(3):308-10.

6. Cooney C, Nagy A. Angio-oedema associated with risperidone. BMJ: British Medical Journal. 1995 Nov 4;31 (7014):1204.

7. Umar MU, Abdullahi AT. Self-limiting atypical antipsychotics-induced edema: clinical cases and systematic review. Indian journal of psychological medicine. 2016 May;38(3):182-8.

8. Terao T, Eło A. Risperidone and allergic reactions.

9. Tunç S, Başbuğ HS. Leg oedema due to low-dose risperidone during maintenance monotherapy of schizophrenia. Psychiatry and Clinical Psychopharmacology. 2018 Jan 2;28(1):104-6.

10. Thakur A, Niranjan V, Rastogi P, Razdan R. Acute oedema associated with risperidone use: a report. General Psychiatry. 2020;33(4).

11.Tamam L, Ozpoyraz N, Unal M. Oedema associated with risperidone. Clinical Drug Investigation. 2002 Jun;22(6):41 1-414.

12. Plesnicar BK, Vitorovic S, Zalar B, Tomori M. Three challenges and a rechallenge episode of angio-oedema occurring in 
treatment with risperidone. European Psychiatry. 2001 Dec;16(8):506-7.

13. Soumya, R. N., Grover, S., Dutt, A., \& Gaur, N. (2010). Angioneurotic edema with risperidone: a case report and review of literature. General hospital psychiatry, 32(6), 646-el.

14. Ravasia S. Risperidone-induced edema. Can J Psychiatry. 2001;46(5):453-4 